\title{
Narrative Understandings of Poverty and Schooling: Reveal, Revelation, Reformation of Mindsets
}

\author{
Darlene Ciuffetelli Parker \\ Brock University, Canada
}

\begin{abstract}
The primary purpose of this research is to examine poverty in a school community from the vantage point of the small narrative discourses that teachers and community members share. These poverty stories become critical counterpoints to meganarrative reforms and top down scripted policy. A second purpose is to introduce three new terms by the author, narrative reveal, narrative revelation, and narrative reformation, as they relate to methodology of narrative inquiry. The goal is to examine storied experience and the complexity of transformational knowledge on the topic of poverty and schooling.
\end{abstract}

\section{Introduction}

The research explores narrative data from a funded project on poverty and education in Ontario, Canada (funded by the Elementary Teachers' Federation of Ontario). The author explores how storied assumptions of children and communities affected by poverty elicit deeper understanding of deficit-based stereotyping. The research makes visible how 'signs of poverty' can be understood as biased assumptions from teachers' own mega-narrative experiences of schooling. The primary purpose is to examine poverty in a school community from the vantage point of the small narrative discourses that teachers and community members share. These stories become critical counterpoint discussions to the mega-narrative [1] reforms that are emphasized in schools of mandated scripted curricula and reform programs. A second purpose is to incorporate three terms by the author, narrative reveal, narrative revelation, and narrative reformation, as they relate to the methodology of narrative inquiry [2] [3]. The goal is to study storied experience and the complexity of transformational knowledge on the topic of poverty and schooling.

\section{Research Background/Rationale}

How do educators ensure challenges of poverty do not obscure what it means to be successful in school?
In Canada, the province of Ontario has changed significantly over the last 30 years. The gap between low income and high income earners has increased in the province and many Ontarians are working longer hours. David Hulchanski [4], associate director for research at the University of Toronto's Cities Centre, accounts a disappearing middle class to four factors: cuts in affordable housing; labour market (it was once very easy to obtain a civil servant job in the 1950 s to 1980 s, but in Canada's current economy, one income can no longer sustain a household); social support cuts, and; discrimination factor $(80 \%$ of high income earners are white where the same percentage in low income is mixed race in regions that are diverse). What is realized is that the human face of this rising inequality is the prevalence of children living in poverty.

Although there have been many public statements supporting the elimination of child poverty for more than 20 years, the child poverty rate has not improved in Canada. Today, 1 in 7 children live in poverty in Ontario, Canada. That statistic rises to 1 in 4, for Aboriginal children living in extreme poverty. Forty-five percent of children living below the poverty line have at least one parent working full time, full year, yet the average low-income family lives $\$ 7000$ per year below the poverty line (poverty is defined as the low income cut off - LICO - line determined by Statistics Canada. LICOs vary by family size and by community size). Rates of poverty are more than double for lone-mother headed households, and children of Aboriginal, racialized, and new immigrant families. In Ontario alone there are over 148,000 children whose families rely on food banks and one in five children has access to licensed child care [5]. There are over 400,000 children and youth living below the low income cutoff and almost have of those are children whose families recently immigrated to Canada [6].

With this overview, what is emphasized in the research herein on poverty and education in Ontario, Canada (and how this research is representative of poverty on a global scale in similar industrialized countries) is how important it is, and how difficult it is too, for educators and the general public to avoid viewing students and their families as lacking. This is referred to as a deficit conceptualization [7] of our 
society and our children. Few are immune to deficit ways of looking at our world because of the very nature of our lived past experiences and the stereotypes that exist in our society. This kind of filter, however, does not help those who live in poverty or the accessibility to the equal education that all children deserve. Deficit thinking essentially perpetuates inequality and the polarization of 'the rich' and 'the poor.' Dudley-Marling [8] further explains that a deficit gaze pathologizes individuals, families, and communities and is grounded in pedagogical practices, says Dudley, and this is why there are disproportionate levels of failure among students who are poor. Dudley-Marling further describes that a deficit gaze does not allow for students' background knowledge and experience to be a part of the curriculum of schools. In other words, students who are non-middle class (being that schools carry out a middle-class curriculum), are set apart, making it difficult for them to feel safe or that they belong in places of schools that render them a risk to the status quo middle class notion of society. Such deficit approaches to education are counter to a democratic society that Dewey [9] so long envisioned.

The rationale of this research paper is to illustrate how one school community, Landmark School, situated in Southern Ontario, shared narratives of personal practice knowledge [10]. Some narratives were revealed as storied assumptions of students and families living in poverty. The participants, over a period of time, revealed various deeply seated assumptions and began interrogating these storied assumptions by reflecting on and using knowledgein-practice to overcome the influence of deficit theory and to further overcome the influence of the ideology of power that permeates traditional white middle class 'curriculum of school' [11]. New narrative understandings of poverty and education led to awareness and reformation of mindsets.

\section{Theoretical Inspirations/Method}

This research observes how one urban school community worked together in order to debunk a deficit model of thinking about poverty and schooling and, instead, viewed its students and families as what was there rather than what was not there, or lacking. The research explores a school community's beliefs and values about children who live in poverty through the starting point of a narrative inquiry framework of living, telling, retelling and reliving [12]. Connelly and Clandinin fore-grounded the importance of experience in education [13]. Narrative inquiry, as a methodology for understanding experience as lived and as told through stories, is an essential way to address problems of knowledge. In the discipline of education, curriculum is often understood within the field and taken up as a mandated course of study to be taught and learned. In contrast, Connelly and Clandinin's [14] notion of curriculum is understood as "one's life course of action" (p.1). Understanding that curriculum is made alongside students, curriculum, in this perspective, is made through the intertwining of the teacher educator's life course of action with his/her teacher candidates' life courses of action. Curriculum can thus be understood as a curriculum of lives, curriculum that is centered in the experiences of several individuals living in relation [15] [16].

In quite the opposite manner, curriculum can also be viewed as top-down strategy implementations - or via the mega-narrative as referred to earlier. In spite of a top-down programmatic reliance, meganarrative pre-scripted curriculum is increasingly evidenced as one of the field's most serious issue as it relates to theory, practice, and policy [17]. A narrative approach, I argue in this paper, is

consistent with more acclaimed and goal-oriented practices in education [18] [19], practices which challenge the dominant white middle class curriculum of schools.

As follows, this paper explores how narrative approaches reveal beliefs and values about children who live in poverty through the starting point of a narrative inquiry framework of living, telling, retelling and reliving (Connelly \& Clandinin, 2006). From the starting point of living, telling, retelling and reliving, I transition the research findings to incorporate narrative in what I have termed narrative reveal, narrative revelation, and narrative reformation in order to illustrate how three participants in the study interrogated their own assumptions and biases about children and families living in poverty. Following in this section, I take up further this transition and the terms that will be used.

We live a life of experience, a course of life. In a Deweyan sense, the curriculum of school is not only about the course of a subject matter, or testing, or accountability; it is also about living a curriculum of life experiences alongside students and families. But, oftentimes as is the world of schooling, curriculum experiences are rooted in the meganarratives [20] of reform programs and formal subject matter curriculum outcomes. Yet, when teachers begin to tell about the curriculum of life experiences and how their teaching is situated within those experiences (which often are in tension within the mega-narrative landscape), the telling may help narratively reveal layers of understanding that they might not have been aware of prior. This in turn helps to reframe perspective on how teachers view their students' context.

Connelly and Clandinin's narrative inquiry terms living, telling, retelling and reliving are useful terms to help describe the process of how teachers can burrow deeply into narratives of experience, as 
stories are told and retold, in order to make new meaning of their knowledge-in-practice and ultimately to use narratives as a way to help reveal hidden biases, as well as to help make newly formed narrative revelations worthy of further interrogation for future practice.

To illustrate, let's take for example the case story of a Kindergarten teacher [21]. In this case, the Kindergarten teacher recounted how she came to a high poverty school after having worked in another more affluent middle to high income school. She had felt comfortable in her prior school milieu because she was familiar with the life style of her students and their families there, having been brought up in a middle income family herself. However, in her current teaching position in the high poverty school, she admitted that she went home on her first day of work and wondered to herself, "What am I doing here at [this] school?" Her prior experience of teaching in a white middle income community and the beliefs she held of teaching to white middle class norms, bumped up and caused tension in her new school community. The Kindergarten teacher's prior notions about schooling in general and about students and families affected by poverty caused her much anguish in how to best understand the lives of students and families there. She received much help from other teachers who supported and mentored her until she was able to, as she reported, "figure it out as well." To explain further what she meant by "figuring it out," she retells this short narrative:

I always tell the story about one of my students who didn't know it was his birthday until he heard it on the P.A. "It's my birthday today?" he asked me. I got it that day. Those are the kids that make it worthwhile. He didn't know [no one told him] it was his birthday. I got it that day. For myself now, after a few years here I go pick the children up at the door and they are smiling. I know it sounds cliché, but they smile, and they're there to greet you every morning when you know what environment they [live]. And we only know the half of it, but I get glimpses when they tell me stories, yet they can still come and say, "Here's my homework, I did it by myself." This is their reality and mine as their teacher.

By telling this story, the Kindergarten teacher reveals a narrative that is rich with meaning and with the realization that her curriculum is embedded in the lives that her and her students live rather than only in a formal (mega-narrative) curriculum of policy and textbook mandates. The phrase in her story, "I got it that day," illustrates that there is a deeper awareness of teaching students from various milieus. To "get it" means that she has begun to unravel the complexities involved in the life course of her curriculum alongside her students, and in adapting to the needs of her students and their families beyond the mainstream (or "middle class" notion) of the formal curriculum of school. In this manner, we see how she has transitioned through a narrative reveal of the tensions she lives (by living, telling and retelling the small narrative as it is juxtaposed to the formal mega-narrative) to how she begins to reframe her experience through her narrative revelation of how her own curriculum of life as an educator is connected directly to the curriculum of life of her students. This narrative revelation is excavated through lived and storied experience - the living and the telling. In this living and telling, and with every new retelling, the complexities of poverty and schooling are understood at a deeper level from the Kindergarten teacher's perspective.

We will return to this storied case at the end of this paper for further consolidation. What follows are findings from the research that helps further narrative understandings of poverty and schooling through the use of narrative reveal, revelation, and ultimately a reformation of mindsets of educators working with students living in poverty.

\section{Data Collection}

Poverty stories are collected and analyzed using the author's narrative terms in order to see change over time of the lived and storied experiences of educators in a large urban school setting in Ontario, Canada. Three narratives of three participants - an administrator, a literacy teacher, and a community member - are examined. The narratives surface from field texts gathered over a longitudinal period of time from a larger research project at the school which is given the pseudonym Landmark School. Other data sources contribute to the rendering of three representational stories including: reflective journals, interviews, and focus group conversations. The stories illustrate how educators' own interrogation of their practices and actions get enacted as biased assumptions of students and families living in poverty and how self-interrogation through the retelling of their stories helps to reform mindsets.

\section{New Understandings: From Narrative Reveal to Narrative Revelation}

\subsection{A Principal's New Understanding}

The new principal of Landmark Park School, Barbara, is a warm welcoming leader who is described as "a bright light that shone hope" in the community. She insures there is an ever-present flow of volunteers at Landmark Park School, and that every teacher and staff member feels valued as a leader in their own right. In fact, Barbara describes herself as a leader of leaders. Her vision for the 
school under her leadership was to model to members in her community how to break the cycle of poverty, having come herself from an impoverished life. Because of her past life experience, Barbara demonstrates an intrinsic knowledge about what students, parents, teachers and community members need and what they expect her to do to meet those needs.

Barbara illustrates her devotion to making the Landmark Park School community welcoming and inclusive. She shared her entry plan as the new Principal of Landmark Park School:

You definitely have to be aware of the depth of the issues with poverty. It's a lot more than money and resources, because then you can be extremely judgmental. And that's something that you have to educate our sponsors and our partners about. So part of my entry plan - the ESL component of the population had been neglected. They had never really felt welcomed into the school, and that was the feedback I got. So, instead of a meet-the-teacher night, we did a multicultural potluck supper. There were the most parents that had ever come out. That was the beginning of the success because ...even though there's not language there's the gesture...

Barbara's narrative reveal shows that she is a committed member of her school community, that she cares immensely about creating a welcoming environment for students and families, and that she strives to make connections to the issues related directly to the context in which students and parents live. Barbara lives out her life as a leader with an identity that depicts she cares about the people she works alongside.

Sometimes, however, the storied script of our life bumps up against assumptions that we take for granted. We see this illustrated in Barbara's case when the meet-the-teacher potluck supper finally took place. Barbara did not take into account a pivotal piece to the multicultural evening she was so earnestly trying to create. Here is Barbara's retelling of her story of the multicultural potluck supper and an assumption she had made:

...[but]... I learned a little bit! It was Ramadan and I didn't think to [do the potluck supper] after Ramadan... They can't eat until the sun goes down, but they all came anyway!

As time has passed, and as Barbara retells her story, a narrative revelation leads her towards a new way of interpreting the landscape wherein she works. She acknowledges that she had made a very big assumption about students and families in her school community and that she would have to begin anew to understand at a much deeper level the cultural diversity of her students' families. This narrative revelation, amidst the larger poverty stories she tells about the school community she serves, illuminates a way of deepening the contextual interpretation of her knowledge and even assumptions (of race, culture, religion, socio economic status, etc). Barbara took action by planning the diversity potluck dinner, but she mistook the forest for the tress, so to speak, leaving her innovative initiative as both a humbling and, as reported by Barbara, embarrassing experience. "They came anyway," she exclaimed. This proclamation was a recognition that parents respected her outreach activity, yet they were unable to eat food on this day as they were fasting. Zeroing in and understanding more fully the cultural make-up of new immigrant families living in poverty was critical, not only to their hardship of financial security, but also to respecting their religion and customs. This led to Barbara's reinvention of her role as a "leader of leaders" which included all teachers, staff members, community workers, and parents too, to lead and make contributions to how the larger narrative of Landmark Park School was enacted. Thus, this narrative revelation became a stop point to gather new information about the context of the school community, rendering the diverse potluck initiative more than just an outreach activity but, rather, a new initiative towards "reaching out" to understand fully the context of students' lives, and their families, without assumptions of how life should be lived.

\subsection{A Literacy Teacher's New Understanding}

A Grade 3 literacy teacher at Landmark Park School looked for ways to bring learning to life for her diverse students, the majority of who lived in poverty. She shared a teaching story of her use of the popular story book Flat Stanley, whose main character is a cut-out figure that travels the world and writes back from his travel destination. Here is the Grade 3 teacher's narrative reveal:

When I started teaching [at Landmark Park School] it was a big shock for me to see all these cultures coming together. I decided a good idea would be to do the Flat Stanley project. There's a book called Flat Stanley, where the main character has a big bulletin board fall on him and he gets flattened, so his parents fold him up and put him in an envelope and mail him off to his best friend in California, because it's cheaper than an airline ticket. I thought I've got all these kids from these different cultures, we'll make Flat Stanleys and mail them back to their relatives (whatever country they were from) and we'll get all this marvelous stuff back.

With all good intentions, the Grade 3 literacy teacher was assuming that she was reaching her students' 
needs by participating in the Flat Stanley project in order to celebrate their diversity and to bring in the connection to students' origin and culture. What she did not anticipate, as the project got underway, was the assumption she had made about the accessibility to students' relatives abroad, or the conditions and dire reality of poverty that far transcended the parameter of Landmark Park School. Here is the Grade 3 teacher's narrative revelation:

[This was a] big learning experience for me. If they had relatives still in the other country, they didn't speak English, they couldn't write back and forth, or at that time a lot of our students were Bosnian Refugees, so there was no one to send them back to. I had one boy in the class. He was a Bosnian refugee, and he had no one to send his Stanley to.

Bosnian refugee children escaped, if they were lucky, to a country such as Canada. Many families lost relatives in the war, and whole families were wiped out. The difficult reality of and various reasons for how students come into poverty was an awakening for the Grade 3 teacher. She went on with her project, but adapted significantly the status quo 'white middle class guideline' of the Flat Stanley book project. Instead, she used her own sister from another far away Canadian province to write back and forth with her students in order to compare urban and rural communities. The literacy teacher explained further that she tried to make the Flat Stanley writing project more feasible for students, even using her own personal family members to do so. Thus, this revelation shows that it was not until she had made authentic connections with the reality of her students' backgrounds and context that she could fully grasp and realize her own biased assumptions. This led to her need to modify her approaches to teaching and, in turn, reframe her mindset of her students and their life experiences. The constant retelling of this story, the literacy teacher reported, was also a reminder to be awake to the realities of her students' lives and, in this fashion, catch herself in any future assumptions she might have about her students. Taking her teacher knowledge-in-practice into account is a viable way to inquire further and probe, to reflect about curriculum-making alongside her students in the context with which she also lives alongside them, making this story revelation about a curriculum of lives, one where she lives alongside her students.

\subsection{A Community Member's Understanding}

A staff member at Landmark Park School described the students' home lives and a very dramatic story was brought to the foreground. During Thanksgiving, the school provides turkeys for several families, as is done is several Ontario schools - a Western cultural celebration in the Canadian landscape. At Landmark Park School one teacher discovered that a family had no oven to cook the turkey in. The staff member described how a teacher went the 'extra mile' and cooked the turkey herself, then delivered the entire holiday meal to her student's family. Here is what the staff member reveals:

Every year we do a turkey dinner here at the school at Christmas time, so last year when we did it we had an inundation of turkeys donated. We had some donated from this company that we buy our nutrition program food from. He donated turkeys. And then the Good Shepherd donated turkeys. We had a lot of extra turkeys, so we started this hamper program. And then the Good Shepherd brought us food to go with these turkeys, so we had a lot of food...

And I can remember the one girl, her mom was so enthralled, just so happy about getting this hamper. But this year... Mary [community worker] cooked one and brought it over to a family [because the family had no oven]...

Such examples from schools going above and beyond to provide charitable donations and actions were plenty. However, what this narrative reveal probes us to think about is the role of the teacher. At what cost is the success of students and families? How is this story an example of belonging to a community that is sustainable? More important of all, are families respected with this act of kindness, or are there other issues inherent in a deficit model of thinking about children who live in poverty, about culture and tradition, and about dignity itself?

One community member, when she heard this story did probe further and commented, "She cooked it herself and brought it over? ...I wonder about that?" This wondering thought, a stop point amidst the drama of the grand narrative of charity, is pivotal to understanding the larger complexity of poverty and how it gets translated into biased notions of people living in poverty and what and how they should be treated, allowed, deserved, the list goes on. The community member flagged this for the larger Landmark Park School teaching faculty, and deeper reflection ensued. Thus, the probing question became a revelation to burrow deeper into the complexities of poverty and to understand deeper too the storied assumptions and biases teachers live as they enact a middle class notion of how tradition should happen juxtaposed with the respect and dignity piece offered. It was the community member's narrative reveal that brought this deeper thinking into play at Landmark Park School. 


\section{Narrative Reformation of Mindset}

\subsection{A Kindergarten Teacher's Reformation}

Let us return to the Kindergarten teacher's story. To reform a way of thinking (i.e. changing one's mindset about storied assumptions, in this case, of children living in poverty) means that one must begin to relive their narrative in a new way. Connelly [22] warns, however, that reliving is difficult work because, "It often comes down to teaching against the narrative grain embedded in...educational narratives"(p.xi). In this case, going against the narrative grain for the Kindergarten teacher means going against the middle class norm of teaching and scripted formula. To go against the mega-narrative grain, in this sense indeed, is difficult work. But to do so will reform her way of understanding curriculum altogether - a curriculum of lives that resists deficit ways of thinking about children affected by poverty. This reliving is important because it brings to the forefront the relationship between life and narrative and the vital significance of narrative to reform our life experiences.

Narrative reformation is unlike the elements of narrative reveal and narrative revelation. The element of narrative reformation is closest to how Connelly [22] applies the concept of reliving. He cautions, "Reliving the untold story is easier said than done...Reliving means living on edge, in tension, among intersecting, competing, narrative threads" (p.xii). Much like reliving, the element of narrative reformation implies, too, that we must live on edge amidst intersecting narrative threads.

Thus, we can begin to ask about the Kindergarten teacher and how she might relive a new narrative with a new mindset. Will she continue to judge whether or not her students should know when it is their birthday or, rather, by reflecting on her retold narrative, will she begin to self-interrogate why this seemed important to her from her prior notion and stance as a "white middle class" teacher? In living out a middle class notion at her prior school, she believed that all students should know their birthdays, celebrate them, even bring in treats for other children to help in the celebration. Perhaps though, with each retelling of this story, her narrative revelation might lead her, by living on edge amongst the intersecting narratives and her middle class notion of a Western mindset of schools, that in fact birthday and birthday celebrations may be a mainstream notion that might be considered a societal pressure in many schools today. The teacher admits, "I always tell the story," which means that she shares this pivotal awakening over and over again. By interpreting, reinterpreting, and retelling her story, the Kindergarten teacher helps solidify her narrative stance and her new awakening about her teaching life alongside her students' lives. This awareness helps reshape her knowledge-in-practice and, in so doing, helps the Kindergarten teacher relive a new understanding of the students in her care. Resisting deficit-based assumptions by interrogating middle class notions of teaching is demonstrated here as a lesson that might be well learned, one that leads ultimately to a narrative reformation of mindset.

\section{Results}

The findings in this paper address how the school community became engaged in life and storied school experiences which juxtaposed the meganarrative of policy and scripted programs through the terms narrative reveal, narrative revelation, and narrative reformation. In this manner, what is avoided is the grand or sacred story [23] of deficit that is so pervasive in the field of education. The research, instead, burrows in on what is possible and revealed through small stories of and about teachers, students, administrators, parents, and community living and working in poverty.

Poverty stories were analyzed using the narrative terms in order to see change over time of the lived and storied experiences of teachers and community members in a large urban school setting in Ontario, Canada. Three narratives of three participants - an administrator, a teacher, and a community member were examined.

Narrative reveal, narrative revelation and narrative reformation are useful terms that provide a framework to excavate storied experiences (and assumptions) that educators and community members may hold in their lived prior experiences about schooling. As Bruner [24] suggests about living an examined life, "If we learn how people put their narratives together...considering as well how they might have proceeded, we might then have contributed something new to that great ideal" ( $\mathrm{p}$. 709). This paper has shown that the small narratives that educators and community members share, when self-interrogated further through retellings of those storied experiences, have the transformational capacity to reform mindset. The terms narrative reveal, narrative revelation and narrative reformation are useful narrative inquiry terms to help burrow deeply into seeing storied assumptions of students and families living in poverty and how teaching is enacted when those assumptions come into play. Narratively inquiring into our storied assumptions by using the three terms can help to restore a more democratic way of viewing our students, rather than defaulting or imposing white middle class societal notions on curriculum and school practices. 


\section{Conclusion}

Analyzing school based narrative inquiry research [25] using the narrative terms of reveal, revelation and reformation resulted in: (1) a storied look at poverty and schooling as lived and experienced over time; (2) an examination of stories people live in and by in contrast to the mega-narratives of mainstream white middle class curriculum; (3) the elements of narrative reveal, narrative revelation, and narrative reformation as an alternative consideration for challenging storied assumptions of children living in poverty, and mainstream white-class curriculum, and practice.

\section{References}

[1] Olson, M. \& Craig, C. (2009). Small stories and megastories: Accountability in balance. Teachers College Record, 111(2), 547-572.

[2] Connelly, F. M., \& Clandinin, D. J. (1990). Stories of experience and narrative inquiry. Educational Researcher, 19(5), 2-14.

[3] Clandinin, D. J., \& Connelly, F. M. (2000). Narrative inquiry: Experience and story in qualitative research. San Francisco: Jossey-Bass.

[4] Global Toronto/Toronto's disappearing middle class. David Hulchanski, University of Toronto. www.globaltoronto.com/Pages/Story (Access Date: 25/9/2011).

[5] Campaign 2000 Report Card (2011). Poverty reduction in an age of uncertainty and change. Toronto: Campaign Ontario 2000.

[6] People for Education (2012). Poverty \& Inequality. The Annual Report on Ontario's Publically Funded Schools, 2012.

[7] Valencia, R. R. (1997). The evolution of deficit thinking: Educational thought and practice.

London. Falmer Press.

[8] Dudley-Marling, C. (2007). Return of the deficit. Journal of Educational Controversy. 2 (1), Winter 2007. http://www.bc.edu/schools/lsoe/facultystaff/faculty/dudley. html (Access Date: 30/03/2013)

[9] Dewey, J. (1938). Experience in education. New York: Collier Macmillan Publishers.

[10] Connelly, F. M., \& Clandinin, D. J. (1988). Teachers as curriculum planners. Toronto, Ontario, Canada: Ontario Institute for Studies in Education Press.

[11] Hollins, E.R. (2011). The meaning of culture in learning to teach: The power of socialization and identity formation. In A.F Ball, \& C.A. Tyson (Eds.), Studying diversity in teacher education. (pp.105-130). New York: American Educational Research Association.
[12] Connelly, F. M., \& Clandinin, D. J. (2006). Narrative inquiry. In J. Green, G. Camilli, \& P. Elmore (Eds.) Handbook of complementary methods in educational research (pp. 477-489). Washington, DC: American Educational Research Association.

[13] Dewey, J. (1938). Experience in education. New York: Collier Macmillan Publishers.

[14] Connelly, F. M., \& Clandinin, D. J. (1988). Teachers as curriculum planners. Toronto, Ontario, Canada: Ontario Institute for Studies in Education Press.

[15] Huber, J., \& Clandinin, D. J. (2005). Living in tension: Negotiating a curriculum of lives on the professional knowledge landscape. In: J. Brophy \& S. Pinnegar (Eds). Learning from research on teaching: Perspective, methodology and representation (pp. 313336). Bingley, UK: Emerald.

[16] Downey, C. A., \& Clandinin, D. J. (2010). Narrative inquiry as reflective practice: Mapping a way of knowing for professional reflective inquiry, XXVII (Chapter 19. New York: Springer.

[17] Craig, C. (2010). Teacher education restructuring: Learning environments and innovative technologies. Paper presented at the Second East Asian Conference on Teacher Education Research, December 2010, Hong Kong.

[18] Darling-Hammond, L.\& Bransford, J. (Eds.) (2005). Preparing teachers for a changing world: What teachers should learn and be able to do. San Francisco: JosseyBass.

[19] Darling-Hammond, L. (2006). Powerful teacher education: Lessons from exemplary programs. San Francisco: Jossey-Bass.

[20] Olson, M. \& Craig, C. (2009). Small stories and mega-stories: Accountability in balance. Teachers College Record, 111(2), 547-572.

[21] Ciuffetelli Parker, D. \& Flessa, J. (2011). Poverty and schools in Ontario: How seven elementary schools are working to improve education. Elementary Teachers Federation of Ontario. Toronto, ON

[22] Connelly, F.M. (2011). Foreword. In J. Kitchen, D. Ciuffetelli Parker, \& D. Pushor (Eds.), Narrative inquiries into curriculum making in teacher education. pp. xi-xvi. Emerald Publishing, UK.

[23] Crites, S. (1971). The narrative quality of experience. Journal of the American Academy of Religion, 39(3), 291-311.

[24] Bruner, J.S. (2004). Life as narrative. Social research. 71(3), 691-710.

[25] Xu, S., \& Connelly, F.M. (2010). Narrative inquiry for school-based research. Narrative Inquiry, 20, 349-370. 